\title{
Feedback to Receivers: Knowledge and Perception of Medical Students in a Public Sector Institute of a Developing Country
}

\author{
Hamza Waqar Bhatti, Syed Muhammad Jawad Zaidi, Mehwish Kaneez, Javeria Awan, \\ Rashid Naeem Khan, and Umair Tahir
}

\section{ABSTRACT}

Background: The practice of effective feedback delivery in medical institutes of developing countries lags behind the modern principles of medical education. This demands the need to understand the students' knowledge and perception regarding received feedback in the setting of a developing country.

\begin{abstract}
Aims: To assess the level of knowledge and perception of feedback among students. To find the correlation between knowledge and perception. To identify problematic areas in feedback delivery and provide recommendations for rectification.
\end{abstract}

Methods: A cross-sectional study conducted in Rawalpindi Medical University Pakistan, in which $\mathbf{4 8 0}$ medical students from 2nd till 5th-year MBBS were evaluated regarding their knowledge and perception about feedback using structured questionnaires.

Results: The students had a good level of knowledge regarding The concept of feedback. However, they had a negative perception of the feedback given to them by their teachers. There was no correlation between mean knowledge and perception scores ( $r=-$ $0.05, p=0.272)$. There was a significant difference between knowledge $(p=0.0004)$ and perception $(p=0.02)$ scores across gender. The difference in mean knowledge scores across academic years was not significant $(p=0.267)$ but this difference was significant for mean perception scores $(p=0.001)$.

Conclusion: Strategies should be adopted to incorporate feedback into the curriculum for improving the quality of medical education in a developing country.

Keywords: feedback, medical education, perception, knowledge.
Published Online: November 14, 2020

ISSN: $2593-8339$

DOI: $10.24018 /$ ejmed.2020.2.6.553

Hamza Waqar Bhatti

Rawalpindi Medical University, Rawalpindi, Pakistan.

(e-mail: hamzawaqarbhatti@gmail.com) Syed Muhammad Jawad Zaidi*

Rawalpindi Medical University,

Rawalpindi, Pakistan.

(e-mail: mjawad927@gmail.com)

Mehwish Kaneez

Rawalpindi Medical University,

Rawalpindi, Pakistan.

(e-mail: mehwish.kaneez ${ }^{\circledR}$ gmail.com) Javeria Awan

Rawalpindi Medical University, Rawalpindi, Pakistan.

Rashid Naeem Khan

Shifa International Hospital, Islamabad, Pakistan.

Umair Tahir

Shifa International Hospital, Islamabad, Pakistan.

*Corresponding author

\section{INTRODUCTION}

Feedback is a piece of honest and impartial information provided to the students which narrates their level of performance and satisfaction of the supervisor in a given task [1]. Feedback is a fundamental component of learning assessment and advancement and it is closely associated with student's motivation and preferences for learning [2]. It can be in the form of praise, constructive criticism, or suggestions and forms an important pillar of a competencybased curriculum [3]. Provision of effective, timely, specific, and concrete feedback assists in the evaluation of the student's performance and narrows the gap between observed and desired performance [4]. Effective feedback delivery regardless of its nature undermines incompetent behavior and helps students to refine their skills and learning abilities. In contrast, inconclusive feedback may be a source of confusion for the students and is associated with incompetency and demotivation [5].

Modern principles of medical education consider feedback an integral part of the medical curriculum as it enables the students to develop a conducive professional behavior towards their course [6]. Literature suggests that feedback should be implemented regularly for teaching medical students because of the diverse nature of the curriculum [6], [7]. Feedback helps medical students to evaluate their learning process and develop a strategic plan for error detection which promotes self-regulated learning [8]. All these factors make the system of feedback from the teachers an integral part of good quality medical [6]-[8] 
Despite the importance of feedback in medical education the literature reviewed suggests that medical students, especially in developing countries, remain unsatisfied with the quality of received feedback whereas, teachers consistently conflict with the idea affirming that they deliver valuable feedback to students [6], [8]. This contrast in perception leads to numerous problem areas in which teachers do not attempt to improve the quality of feedback, which creates confusion and demotivation among the students that affect their learning capabilities [9]. In addition to understanding the importance of feedback, it is also important for the teachers to be aware of how students perceive and relate to the delivered feedback [10]. The dilemma is that this concept is frequently ignored due to conventional teacher-centered teaching methods in developing countries. It has been proposed that there might be a disparity between the received and perceived feedback [11]. Thus, the major factors associated with making the feedback beneficial are its recognition and the way it is perceived by the students [10], [11].

Although feedback has proven to be a fulcrum in medical education, the concept of assessing knowledge and perception of students regarding feedback is an underresearched area, especially in developing countries. This topic has begun to gain attention in recent years in some developed countries. A study conducted in the United Kingdom reported that the majority of students valued the importance of feedback and had adequate knowledge regarding purpose, timing, and benefits of feedback but $65 \%$ of those students were not satisfied with the received feedback considering it insufficient [12]. Naomi E. Winstone et al. highlighted that poor knowledge of students about the concept of feedback, a low insight of utilizing feedback into strategic action, and less receptivity are a few barriers to effective feedback delivery [13].

The dilemma is the lag in effective feedback delivery in public sector institutes of developing countries due to extensive patient load and teacher-centered teaching [14]. These factors require a need to assess the knowledge and perception of students regarding the feedback they receive. This will help in the identification of barriers to effective feedback delivery in a developing country. The current study thus aims to assess the knowledge and perception of undergraduate medical students towards feedback. The study also aims to identify potentially problematic areas in feedback delivery as perceived by the students and to provide practical recommendations to overcome these problems.

\section{METHODS}

This cross-sectional study was conducted from December 2019 to February 2020 that included 480 MBBS students from Rawalpindi Medical University, Pakistan. In Rawalpindi Medical University (RMU), the MBBS course is divided into five academic years and education is divided into two phases. The preclinical phase includes the 1 st and 2nd year while the clinical phase includes students from 3rd, 4th, and 5th-year. Only those students were included in the study who had completed at least one academic year in the institution. Keeping in mind the inclusion criteria, the students of first-year MBBS were excluded from the study as they were yet to complete their academic year. A stratified random sampling technique was used to collect data in which an equal number of male and female students (60 males and 60 females) from $2^{\text {nd }}, 3^{\text {rd }}, 4^{\text {th }}$, and $5^{\text {th }}$ year were approached. The knowledge and perception of students regarding feedback were assessed using structured questionnaires. The purpose of the study was explained properly to the students with informed consent and confidentiality was maintained. The study was ethically approval from the institutional research forum of Rawalpindi Medical University. Two scales were used in the study.

A twenty-item scale containing true-false questions was used to assess the knowledge about feedback. Each item was scored 1 for true and 0 for false except for item no. 7, 11, $12,15,14$ and 18 which are reversed scored ( 0 for true and 1 for false). The scale was divided into 6 domains which include the following:

1. Content of feedback (Items 1, 12 and 16).

2. Occasion of Feedback (Items 6, 8 and 10).

3. Givers and Receivers of Feedback (Items 7, 11 and 19).

4. Mode and Mechanism of Feedback (Items 4, 5, 9, 15 and 18).

5. Reason feedback is fed back (Items 2, 313 and 17).

6. Setting of Feedback (Items 14 and 20).

The maximum score for the scale was 20 . Scores of 16 or more indicated a good level of knowledge, scores between 11-15 indicates an average level of knowledge while scores below 10 indicate low or insufficient knowledge regarding feedback given by teachers.

A fifteen-item scale was used to access perception of feedback among undergraduates and responses were collected on a five-point Likert scale ( $0=$ strongly disagree, $1=$ disagree, $2=$ neutral, $3=$ agreeable, $4=$ strongly agreeable) . Ten out of fifteen negative items (Item no. 1, 2, 3, 5, 6, 8, 9, 11,13 and 15) are reversed scored. The mean score of each item was interpreted as; 0-1.99: more negative than positive perception on feedback, 2-2.99: neutral perception towards feedback, 3.0-4.00: more positive than negative perception towards feedback. The scale was divided into four domains which included

1. Practice of feedback (Items 1, 9 and 14)

2. Factors influencing feedback (Items 2, 11 and 15)

3. Teacher's skills in giving feedback (Items 3, 4, 6, 8 and 10)

4. Students' readiness in receiving feedback (Items 5, 7, 12 and 13)

The total perception score was 60 . Scores ranging from 0 30 indicated a negative perception, scores ranging from 31 45 illustrated a neutral level of perception, and scores between 46-60 showed a more positive perception regarding feedback.

The permission to use both of these scales was taken from the author of the referenced study [8]. The questions of the scales were a bit modified according to our setup for prompt understanding. The scales for assessing perception and knowledge were checked for reliability by Cronbach's alpha value. The normality of the data was assessed using the Shapiro-Wilk test. The data was presented in the form of frequencies, means, standard deviations, and analytical tests. 
Mann-Whitney $U$ and Kruskal Wallis tests were used to assess differences in median knowledge scores across gender and academic years respectively. Independent sample t-test and One-way ANOVA with Tukey Post-hoc analysis was used to assess differences in perception scores across gender and academic years respectively. The correlation between knowledge and perception was checked by using Spearman's correlation. P-value of less than 0.05 was considered statistically significant. Data were analyzed using SPSS version 25.0.

\section{Results}

The Cronbach's alpha values for knowledge and perception subscale were 0.74 and 0.77 respectively. A total of 480 medical students from 2nd to 5th-year MBBS participated in the study. Table 1 shows the information of the study participants. There was a statistically significant difference in the mean knowledge scores across gender ( $p$ $=0.0004$ ) with females having a higher mean knowledge score than males. The difference in perception scores across gender was also statistically significant $(\mathrm{t}(478)=2.342$, $\mathrm{p}=0.02$ ), with male students having higher mean perception scores than females. This is shown in Table 2. Spearman's correlation between knowledge and perception scores showed a negative but insignificant $(\mathrm{r}=-0.05, \mathrm{p}$ value $=0.272$ ).

There was a statistically significant difference in the mean perception scores across academic years ( $p$-value $=0.001$ ). Tukey post-hoc analysis revealed a significant difference in mean perception scores of 2 nd year with that of $3 \mathrm{rd}$ (pvalue $=0.007)$ and 5 th year $(0.001)$. However, there was no such difference in the mean knowledge scores. Table 3 and Table 4 show the comparison of means perception and knowledge scores across each academic year. Table 5 highlights individual items and areas of concern regarding feedback delivery. Most of the Individual items had low mean scores indicating a more negative perception regarding the received feedback.

TABLE I: DETAILS OF PARTICIPANTS (STRATIFIED RANDOM SAMPLING WAS

\begin{tabular}{cccccc}
\multicolumn{7}{c}{ USED) } \\
\hline Variable & $\begin{array}{c}\text { 2nd year } \\
\mathrm{n}=120\end{array}$ & $\begin{array}{c}\text { 3rd year } \\
\mathrm{n}=120\end{array}$ & $\begin{array}{c}\text { 4th year } \\
\mathrm{n}=120\end{array}$ & $\begin{array}{c}\text { 5th year } \\
\mathrm{n}=120\end{array}$ & $\begin{array}{c}\text { total } \\
\mathrm{n}=480\end{array}$ \\
\hline $\begin{array}{c}\text { Age(years) } \\
19-21\end{array}$ & 113 & 85 & 25 & 4 & 227 \\
$22-24$ & 7 & 33 & 93 & 108 & 241 \\
Above 24 & 0 & 2 & 2 & 8 & 12 \\
Gender & & 60 & 60 & 60 & 240 \\
Male & 60 & 60 & 60 & 60 & 240 \\
Female & 60 & 60
\end{tabular}

TABLE II: MEAN PERCEPTION AND KNOWLEDGE SCORES ACROSS GENDER

\begin{tabular}{cccc} 
Variable & Gender & $\begin{array}{c}\text { Median (IQR)/Means } \\
(\mathrm{SD})\end{array}$ & p-values \\
\hline Mean knowledge & female (240) & $17(7-20)$ & \\
scores & male (240) & $16(10-20)$ & $0.0004^{*}$ \\
Mean perception & male (240) & $27.54 \pm 5.67$ & \\
scores & female (240) & $26.24 \pm 6.46$ & $0.02^{* *}$ \\
\hline
\end{tabular}

*Mann-Whitney U Test.

**Independent samples t-test.

TABLE III: COMPARISON OF MEAN PERCEPTION SCORES ACROSS ACADEMIC YEARS

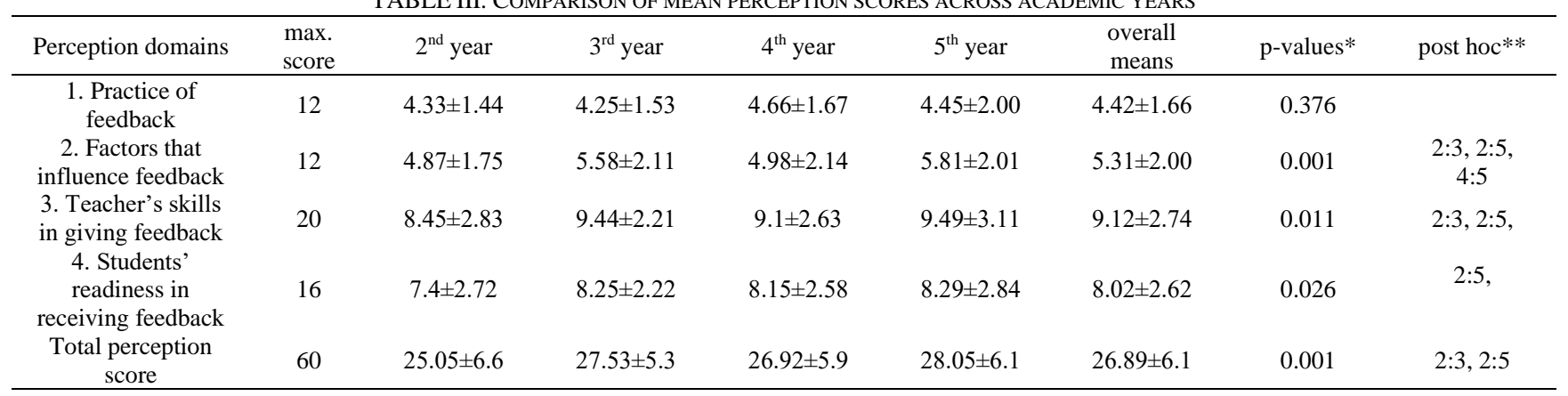

*p-values obtained by One-way ANOVA

**posthoc analysis showing only statistically significant differences between academic years $(\mathrm{p}<0.05)$

TABLE IV: COMPARISON OF MEDIAN KNOWLEDGE SCORES ACROSS ACADEMIC YEARS

\begin{tabular}{|c|c|c|c|c|c|c|c|}
\hline Knowledge domains & $\begin{array}{c}\max \\
\text { score }\end{array}$ & $\begin{array}{c}2^{\text {nd }} \text { year } \\
\text { median (IQR) }\end{array}$ & $\begin{array}{l}\text { 3rd year median } \\
\text { (IQR) }\end{array}$ & $\begin{array}{c}\text { 4th year median } \\
\text { (IQR) }\end{array}$ & $\begin{array}{c}\text { 5th year median } \\
\text { (IQR) }\end{array}$ & $\begin{array}{c}\text { overall } \\
\text { median (IQR) } \\
\end{array}$ & p-value* \\
\hline 1. Content of feedback & 3 & $2(1-3)$ & $3(1-3)$ & $2(0-3)$ & $3(1-3)$ & $3(0-3)$ & 0.001 \\
\hline 2.Occasion of feedback & 3 & $3(1-3)$ & $3(1-3)$ & $2.5(1-3)$ & $2.5(1-3)$ & $3(1-3)$ & 0.326 \\
\hline $\begin{array}{l}\text { 3. Givers and receivers } \\
\text { of feedback }\end{array}$ & 3 & $2(0-3)$ & $2(0-3)$ & $2(0-3)$ & $2(0-3)$ & $2(0-3)$ & 0.046 \\
\hline $\begin{array}{l}\text { 4. Mode and mechanism } \\
\text { of feedback }\end{array}$ & 5 & $4(2-5)$ & $4(1-5)$ & $4(1-5)$ & $4(1-5)$ & $4(1-5)$ & 0.097 \\
\hline $\begin{array}{l}\text { 5. Reason feedback is } \\
\text { fed back }\end{array}$ & 4 & $4(3-4)$ & $4(0-4)$ & $4(1-4)$ & $4(1-4)$ & $4(0-4)$ & 0.001 \\
\hline 6. Setting of feedback & 2 & $1.5(0-2)$ & $2(0-2)$ & $2(0-2)$ & $2(0-2)$ & $2(0-2)$ & 0.033 \\
\hline Total knowledge score & 20 & $16(12-20)$ & $16(10-19)$ & $16(7-20)$ & $16(10-20)$ & $16(7-20)$ & 0.267 \\
\hline
\end{tabular}

*p-values obtained by Kruskal Wallis test. 
TABLE V: MEAN SCORE OF STUDENTS' PERCEPTIONS TOWARDS FEEDBACK FOR EACH ITEM

\begin{tabular}{|c|c|c|}
\hline Item\# & Domains and items & Mean \pm S.D \\
\hline \multicolumn{3}{|c|}{ Domain 1. Practice of feedback } \\
\hline 1 & Feedback is not frequently given by the teachers & $1.29 \pm 0.92$ \\
\hline 9 & The received feedbacks are more evaluative than descriptive. & $1.47 \pm 0.89$ \\
\hline 14 & Time is allotted for feedback sessions after completion of the teaching period & $1.70 \pm 0.93$ \\
\hline \multicolumn{3}{|c|}{ Domain 2. factors influencing feedback } \\
\hline 2 & Feedback is usually given by the teachers rather than one-self and class fellows. & $1.77 \pm 0.95$ \\
\hline 11 & $\begin{array}{l}\text { Feedback is not given immediately and is delayed. E.g. Feedback will be given in the next class stating how the } \\
\text { previously given tasks could have been performed better }\end{array}$ & $1.33 \pm 0.82$ \\
\hline \multicolumn{3}{|c|}{ Domain 3. teacher's skill in giving feedback } \\
\hline 3 & $\begin{array}{l}\text { Feedback given to you is in equal quality with your performances. E.g.: you may think that your performance } \\
\text { was up to the mark but the instructor may have given poor feedback on your performance on a certain task. }\end{array}$ & $1.79 \pm 0.96$ \\
\hline 4 & The feedback given to you are constructive and immediate & $2.09 \pm 0.98$ \\
\hline 6 & $\begin{array}{l}\text { Positive and negative feedback is given in the form of appraisal without stating why it was well or poorly } \\
\text { performed }\end{array}$ & $1.60 \pm 0.71$ \\
\hline 8 & $\begin{array}{l}\text { There are gender biases by the instructors in giving feedback to the students e.g. Male students receive } \\
\text { feedback more harshly as compared to the female students }\end{array}$ & $1.41 \pm 0.85$ \\
\hline 10 & Feedback given is in a specific manner rather than generalized feedback. & $2.24 \pm 0.98$ \\
\hline \multicolumn{3}{|c|}{ Domain 4. students' readiness in receiving feedback } \\
\hline 5 & $\begin{array}{l}\text { I feel sad, offended, critiqued or demotivated by the feedback that is given to you either from the teachers or } \\
\text { class fellows }\end{array}$ & $1.97 \pm 1.13$ \\
\hline 7 & Feedbacks given are perceived as credible, knowledgeable and well-intentioned & $2.33 \pm 1.06$ \\
\hline 12 & There is always a response and interaction between students and teachers during the feedback session & $1.91 \pm 0.73$ \\
\hline 13 & I feel insulted by negative reviews during the feedback session and I tend to dislike the feedback session & $1.81 \pm 0.66$ \\
\hline
\end{tabular}

\section{DISCUSSION}

Feedback is a fundamental component of good quality medical education and studies have demonstrated that efficacious feedback delivery is associated with better learning outcomes [2], [13]. Even with all the progress that has been made in medicinal education up until the $21 \mathrm{st}$ century, the practice of delivering regular and timely feedback lags [7], [15], and the results of our study are according to this finding.

Our study showed that even though knowledge about the concept of feedback was good among students but the perception was negative. The probable reasons may be the conventional teacher-centered teaching and less concern of the teachers towards the students due to excessive workload, long duty hours, and patient care priority in the public sector hospital [16]. A study done in the United Kingdom illustrated that the students had adequate knowledge and a positive perception of the received feedback [17] which is contrary to our study. While another study conducted in Saudi Arabia reported a negative perception of students, a finding similar to our study [18]. Moreover, there was no significant correlation between the knowledge and perception scores which is in accordance with another study [8]. The difference in mean knowledge scores across gender indicated that females were more aware of how ideal feedback should be as compared to male students. However, a study in Malaysia concluded that there was no difference between the students' level of knowledge of feedback across gender [8].

Studies in developed countries have shown that the implementation of an effective feedback delivery system is associated with proper teacher evaluation, better available resources, advanced infrastructure, and new learner-centered teaching methodologies [3], [17], [19]. This demands the need for implementation of an effective feedback delivery system in medical institutes of developing countries for better medical education
The pre-clinical year students (2nd-year) were more dissatisfied with the received feedback than clinical year students (3rd, 4th, and 5th-year). Another study also concluded that effective and timely feedback is required to reinforce clinical knowledge in the pre-clinical curriculum [20]. However, the mean perception scores of each year showed that all students perceived the received feedback negatively indicating the need for radical interventions in the feedback delivery system.

The low mean scores in individual items of the perception scale indicate the need for interventions to resolve the problematic areas. Item no. 1 (feedback is not frequently given), item no. 14 (Time is allotted for feedback sessions) and the item no. 11 (delayed feedback is given) showed that untimely, ineffectual, and unproductive feedback is delivered to the students. The reasons may include undermined importance of feedback, frequent delays, and the busy schedule of the teachers. Similar barriers are highlighted in these studies [5], [13], [21]. This suggests that raising awareness of the importance of feedback, planning, and inclusion of feedback in the schedule along with reevaluation of feedback practices might result in improved utilization of feedback for the development of an outcomebased curriculum [8], [22]. The item no 9 (feedback received is more evaluative rather than descriptive) indicated that mentors gave brief and evaluative feedback rather than describing the strengths and weaknesses of the performance. This suggests that the delivery of evidencebased, descriptive, and optimal quality feedback is missing in our setup. Bing-You $\mathrm{R}$ et al. also concluded that the development of an effective feedback delivery system for students is the need of the time and there is a lack of recommendations for its improvement [23].

Moreover, the low mean scores in the item no. 8 (there are gender biases in giving feedback), item no. 5 (I feel sad or critiqued by the way feedback is given) and item no. 13 (I feel insulted by the negative reviews) suggest that students may often misperceive the received feedback leading to discouragement and demotivation. Thus, teachers should be familiar with this idea of how students perceive the 
delivered feedback. Moreover, the feedback should be delivered in a proper way and proper setting. Guidelines developed by Janet Lefroy et al. recommend that harsh and improper feedback has an emotional impact on students which may lead to emotional distress influencing their ability to act upon the feedback given, a theory that should be considered while delivering feedback [24].

In the study, only 3 out of 15 items reported a neutral perception of students. This is a highly alarming situation indicating that the true status of the feedback system should be reported immediately to the authorities so that they can make improvements to the problematic areas. A study conducted in Australia reported that more than $93 \%$ of students seriously considered the feedback provided to them in a given task and more than $88 \%$ of students reported that feedback helped them improve their performance [25]. This proves that the trend of feedback perception of the students in a developed country setting is more positive due to which they can identify barriers in learning and improve learning outcomes.

In the study, we only assessed a fixed set of factors and did not evaluate qualitative aspects which may influence feedback. The addition of qualitative elements in the study would have made the results more enlightening. Despite this limitation, the findings of our study should be given serious consideration as it highlights many shortcomings regarding the provided and perceived feedback.

Similar studies should be conducted in other study settings so that the true status of knowledge and perception regarding feedback can be assessed. This will aid in the identification of barriers to effective feedback delivery. Thus, our study opens up horizons for future research in the field of medical education.

\section{CONCLUSIONS}

The students had good knowledge regarding the concept of feedback and they supported the importance of feedback in the curriculum. However, they perceived the delivered feedback to be more negative than positive suggesting the need for re-evaluation of the feedback process. The results of the study help in understanding the students' perspective of received feedback and highlights the true status of the delivered feedback. Strategies should be adopted to incorporate feedback into the curriculum for improving the quality of medical education in a developing country.

\section{REFERENCES}

[1] Jug R, Jiang XS, Bean SM. Giving and Receiving Effective Feedback A Review Article and How-To Guide. Arch Pathol Lab Med. 2019 Feb;143(2):244-50.

[2] Alhaqwi AI. Importance and process of feedback in undergraduate medical education in Saudi Arabia. Saudi J Kidney Dis Transpl. 2012;23(5):1051-5.

[3] Marcotte L, Egan R, Soleas E, Dalgarno NJ, Norris M, Smith CA. Providing quality feedback to general internal medicine residents in a competency-based assessment environment. Can Med Educ J. 2019;10(4):e32-47.
[4] Shrivastava S, Shrivastava P, Ramasamy J. Effective feedback: An indispensable tool for improvement in quality of medical education. J Pedagog Dev. 2010;3(1):12-20.

[5] Mulliner E, Tucker M. Feedback on feedback practice: perceptions of students and academics. Assess Eval High Educ. 2017;42(2):266-88.

[6] Nottingham S, Henning J. Feedback in clinical education, part II: Approved clinical instructor and student perceptions of and influences on feedback. J Athl Train. 2014;49(1):58-67.

[7] Alfehaid LS, Qotineh A, Alsuhebany N, Alharbi S, Almodaimegh H. The Perceptions and Attitudes of Undergraduate Healthcare Sciences Students of Feedback: A Qualitative Study. Heal Prof Educ. 2018;4(3):186-97.

[8] Naekashri Jothi MSBYD. Knowledge and Perception of Medical Students on Feedback. Educ Med J. 2015;7(5):44-55.

[9] Oktaria D, Soemantri D. Undergraduate medical students' perceptions on feedback-seeking behaviour. Malaysian J Med Sci. 2018;25(1):7583.

[10] D. Rowe A, N. Wood L. Student Perceptions and Preferences for Feedback. Asian Soc Sci. 2009;4(3)

[11] Bowen L, Marshall M, Murdoch-Eaton D. Medical Student Perceptions of Feedback and Feedback Behaviors Within the Context of the "educational Alliance." Acad Med. 2017;92(9):1303-12.

[12] Hall M, Hanna LA, Quinn S. Pharmacy students' views of faculty feedback on academic performance. Am J Pharm Educ. 2012;76(1):17.

[13] Winstone NE, Nash RA, Rowntree J, Parker M. 'It'd be useful, but I wouldn't use it': barriers to university students' feedback seeking and recipience. Stud High Educ [Internet]. 2017;42(11):2026-41. Available from: https://doi.org/10.1080/03075079.2015.1130032

[14] Pokhrel R, Tandon A, Bhatnagar R. Integrated Versus Traditional Method in Basic Medical Science Education: A Comparative Study in an Indian Medical College. Med J Shree Birendra Hosp. 2016 Jul 5; $15: 32$.

[15] Griffiths JM, Fcfp C, Luhanga U, Med M, Mcewen LA, Schultz K Dalgarno N. Teaching Moment | Occasion d'enseignement Promoting high-quality feedback Tool for reviewing feedback given to learners by teachers. Can Fam Physician • Le Médecin Fam Can | [Internet]. 2016; 62:600-2. Available from: www.cfp.ca

[16] Imran N, Haider I, Iqtadar S, Bhatti M, Med P. Unhappy doctors in Pakistan: What are the causes and what can be done? Pakistan J Med Sci. 2011 May;27.

[17] Tuff LC. Undergraduate orthoptic students' perception of feedback during clinical placement. Br Ir Orthopt J. 2012;10(0):35.

[18] Al-Mously N, Nabil NM, Al-Babtain SA, Fouad Abbas MA. Undergraduate medical students' perceptions on the quality of feedback received during clinical rotations. Med Teach. 2014 Apr;36 Suppl 1: S17-23.

[19] Shaw R, Reid W, Parker Q. Macquarie University ResearchOnline. Publ Astron Soc PACIfiC. 2007; 119:19-29.

[20] Egnew T, Wilson H. Faculty and medical students' perceptions of teaching and learning about the doctor-patient relationship. Patient Educ Couns. 2009 Sep 1; 79:199-206.

[21] Ansari T, Usmani A. Students perception towards feedback in clinical sciences in an outcome-based integrated curriculum. Pakistan J Med Sci. 2018;34(3):702-9.

[22] Agarwal A, Rao S. Do Students Value Feedback? - Perception, Attitude and Practices of Students Regarding Role of Feedback in Their learning. Asian J Res Med Pharm Sci. 2018;2(4):1-10.

[23] Bing-You R, Hayes V, Varaklis K, Trowbridge R, Kemp H, McKelvy D. Feedback for Learners in Medical Education: What Is Known? A Scoping Review. Acad Med. 2017 Sep;92(9):1346-54.

[24] Lefroy J, Watling C, Teunissen PW, Brand P. Guidelines: the do's, don'ts and don't knows of feedback for clinical education. Perspect Med Educ. 2015;4(6):284-99.

[25] Strong J, Hughes C, Wilson W, Arnott W, Isles R, Bennison A Perceptions of Feedback among Undergraduate and Postgraduate Students of Four Health Science Disciplines. Internet J Allied Heal Sci Pract. 2012;10(4):11. 